\title{
ARRANJOS DE PLANTAS DE MANDIOCA E MILHO EM CULTIVO SOLTEIRO E CONSORCIADO: CRESCIMENTO, DESENVOLVIMENTO E PRODUTIVIDADE ( $\left.{ }^{1}\right)$
}

\author{
ALFREDO SCHONS $\left({ }^{2}\right)$; NEREU AUGUSTO STRECK $\left({ }^{3 *}\right)$; LINDOLFO STORCK $\left({ }^{3}\right)$; GALILEO ADELI BURIOL $\left({ }^{3}\right)$; \\ ALENCAR JUNIOR ZANON $\left({ }^{4}\right)$; DIEGO GARRIDO PINHEIRO $\left({ }^{4}\right)$; BRUNO KRAULICH $\left({ }^{4}\right)$
}

\begin{abstract}
RESUMO
O objetivo deste trabalho foi quantificar o crescimento, o desenvolvimento e a produtividade da mandioca e do milho em diferentes arranjos de plantas em cultivo solteiro e consorciado considerandose duas épocas de semeadura do milho. O experimento foi desenvolvido em Santa Maria (RS). A mandioca, variedade RS 13, foi plantada em 27/9/2005. O milho, variedade BRS Missões, foi semeado em duas épocas: 2/11/2005 e 29/11/2005. O delineamento experimental foi o de blocos completos ao acaso com 12 tratamentos e três repetições. Foram medidos parâmetros de crescimento (altura de plantas e área de folhas), desenvolvimento (filocrono, número final de folhas e duração de fases de desenvolvimento) e os componentes de produção das duas culturas. Foi calculada a soma térmica de algumas fases de desenvolvimento (usando-se uma temperatura base de $14{ }^{\circ} \mathrm{C}$ para mandioca e de $10{ }^{\circ} \mathrm{C}$ para milho) e determinado o filocrono. $\mathrm{O}$ crescimento e o desenvolvimento das duas espécies não foram afetados pelo arranjo de plantas, tanto em cultivo solteiro como em consórcio. O maior uso eficiente da terra (UET) foi obtido no consórcio de mandioca com milho, com a mandioca cultivada em fileiras duplas de 1,6 $\mathrm{x}$ $0,5 \times 0,6 \mathrm{~m}$ e uma fileira de milho a $0,8 \times 0,21 \mathrm{~m}$ ou duas fileiras de $0,4 \times 0,42 \mathrm{~m}$ entre as fileiras duplas de mandioca e o milho semeado na emergência da mandioca.
\end{abstract}

Palavras-chave: arranjo de plantas, competição de plantas, soma térmica, filocrono, emissão de folhas.

\section{ABSTRACT \\ PLANT SPACING IN MONOCROPPING AND INTERCROPPING OF CASSAVA AND MAIZE: GROWTH, DEVELOPMENT, AND YIELD}

The objective of this study was to quantify the growth, development, and yield of cassava and maize in different plant spacings in monocropping and intercropping systems, considering two sowing dates of maize. The experiment was carried out in Santa Maria, RS, Brazil. The cassava variety RS 13 was planted on September 27, 2005. The maize variety BRS Missões was sown on two dates: November 2, 2005 and November 29, 2005. The experimental design was a complete randomized blocks with 12 treatments and three replications. Growth (plant height and leaf area), development (phyllochron, final leaf number and duration of developmental phases), and yield parameters of both crops were measured. Thermal accumulation (assuming a base temperature of $14{ }^{\circ} \mathrm{C}$ for cassava and $10{ }^{\circ} \mathrm{C}$ for maize) of some developmental phases and the phyllochron were calculated. Growth and development were not affected by plant spacing in both monocropping and intercropping. The highest land use efficiency was obtained by intercropping cassava and maize, with cassava planted in a double row spacing of $1.6 \times 0.5 \times 0.6 \mathrm{~m}$ and maize in a single row spaced $0.8 \times 0.21 \mathrm{~m}$ or two rows of maize spaced $0.4 \times 0.42 \mathrm{~m}$ between the double rows of cassava, with maize sown on cassava emergence.

Key words: plant distribution, plant competition, thermal accumulation, phyllochron, leaf emergence.

$\left({ }^{1}\right)$ Recebido para publicação em 31 de janeiro de 2007 e aceito em 3 de setembro de 2008.

$\left({ }^{2}\right)$ Programa de Pós-graduação em Agronomia, Universidade Federal de Santa Maria (UFSM) e Associação Riograndense de Empreendimentos de Assistência Técnica e Extensão Rural (ASCAR-EMATER/RS). E-mail: aschons@emater.tche.br

$\left({ }^{3}\right)$ Departamento de Fitotecnia, Centro de Ciências Rurais (CCR), UFSM, Avenida Roraima, 1000, 97105-900, Santa Maria (RS), Brasil. E-mail: nstreck1@smail.ufsm.br $\left(^{*}\right)$ Autor correspondente.

$\left({ }^{4}\right)$ Curso de Agronomia, CCR, UFSM. 


\section{INTRODUÇÃO}

A mandioca (Manihot esculenta Crantz) é uma cultura importante pela sua rusticidade e desempenho satisfatório em condições de solos de baixa fertilidade e em diferentes climas de várias regiões do Brasil, estando presente na maioria das pequenas propriedades familiares, sendo importante fonte de carboidratos na alimentação humana e animal. A produção nacional de mandioca somou, em 2006, 26,6 milhões de toneladas de raízes em 1,89 milhões de hectares, com produtividade média de $14 \mathrm{t} \mathrm{ha}^{-1}$. Apesar de ser cultivada em todo o país, a produção de mandioca concentra-se em três Estados, que detém $50 \%$ da produção brasileira: Pará $(5,1$ milhões de toneladas, ou $19,1 \%$ da produção nacional), Bahia $(4,4$ milhões de toneladas, ou 16,5\%) e Paraná (3,8 milhões de toneladas, ou 14,4\%) (IвGE, 2007).

O milho (Zea mays L.) é o $3 .^{\circ}$ cereal mais produzido no mundo, sendo uma cultura presente na maioria das pequenas propriedades familiares do Brasil, e utilizada principalmente para alimentação dos animais (pasto verde, silagem e grãos), além dos grãos representarem uma fonte de renda ao agricultor (BARCELLOS, 1999). Na safra de $2006 / 2007$, a produção mundial foi de 682,1 milhões de toneladas de grãos em uma área de 158,2 milhões de hectares. No Brasil, a produção foi de 40,5 milhões de toneladas em uma área de 12,9 milhões de hectares (Usda, 2007). Nas pequenas propriedades familiares, a utilização de variedades ao invés de híbridos de milho é vantajosa, pois as variedades permitem o uso de sementes próprias em cultivos subseqüentes, e assim o custo de produção é menor.

Uma das características da pequena propriedade rural do Rio Grande do Sul é o plantio de várias culturas, porém quase sempre, cultivadas de forma solteira (BARCELlOS, 1999). No entanto, o cultivo consorciado de duas culturas, como a mandioca e milho, pode ser uma alternativa para melhorar o aproveitamento da área e a ocupação do solo gerando alimento e renda, sendo, portanto, opção importante na agricultura familiar desse Estado.

Vários são os trabalhos de pesquisa com mandioca e milho, porém estes têm priorizado aspectos como produtividade, fertilidade, densidade de plantas e espaçamentos ou arranjos de plantas (Almeida, 1982; Ceretta, 1986; Mattos et al., 2005a,b). Atualmente, agricultura de precisão, combinada com a disponibilidade de novos genótipos, requer novos estudos sobre as combinações da distribuição espacial das plantas no dossel, buscando-se maximizar a produtividade biológica e econômica, tanto em cultivo solteiro como no sistema de cultivos consorciados.
O grande desafio no estabelecimento de sistemas consorciados está na seleção das culturas e do manejo, tendo como metas a maximização no uso do solo e atender aos interesses do agricultor. Em sistemas consorciados de plantas se estabelecem relações complexas entre as culturas, podendo resultar em inibição e cooperação mútuas ou compensação (Ceretta, 1986).

Dentre as vantagens do sistema consorciado quando comparado ao cultivo solteiro, pode-se destacar o aumento na produtividade por unidade de área (Mattos et al., 2005a,b). RaO e Morgado (1985), relataram aumentos que variam de $60 \%$ a $90 \%$ de produtividade em plantios de mandioca consorciada com diversas culturas. Incrementos de produtividade da mandioca, variedade BGM 116, de 36 a $85 \%$ foram obtidos quando consorciada com milho, variedade BR 105 , em espaçamentos de fileira dupla de mandioca que variaram de $2,0 \times 0,5 \times 0,5 \mathrm{~m}$ a $2,0 \times 0,7 \times 0,7 \mathrm{~m}$ (MAtTos et al. 1983).

Na cultura da mandioca, o plantio pode ser realizado com plantas dispostas em fileiras simples e em fileiras duplas (Bueno, 1985; CERETTA, 1986; Silva e Ceretta, 1986; Tánora e Melo, 1993). O plantio em fileiras duplas é uma opção de arranjo em que se agrupam duas fileiras. A disposição em fileiras duplas tem algumas vantagens em comparação ao sistema de fileiras simples como maior facilidade de trabalho com equipamentos e implementos agrícolas, diminuição de custos de produção pela redução de mão-de-obra, pois diminuem os tratos culturais, maior possibilidade da utilização do espaço entre fileiras duplas com outra espécie, maior facilidade para inspeção do cultivo, aumento da produtividade biológica devido ao efeito de bordadura, redução da quantidade de fertilizantes e o uso mais racional da terra (MAtTos, 1979; Almeida, 1982; Mattos et al. 1985). O espaçamento usado na cultura da mandioca quando cultivada em fileiras simples é variável, como por exemplo, de $1,0 \times 1,0 \mathrm{~m}$, de $1,0 \times 0,8 \mathrm{~m}$ e de $1,2 \times 0,8 \mathrm{~m}$ (OYARZÁbal, 1995). Quando em linhas duplas, os espaçamentos utilizados são de 2,0 × 0,6 × 0,6 m ou de 2,0 $\times 0,5 \times$ 0,5 m (Mattos et al., 1985; TÁvora e Melo, 1993). Nestes espaçamentos, tanto em fileiras simples como em fileiras duplas, a densidade de plantas é de aproximadamente 16.000 plantas por hectare.

Ao comparar o sistema de fileiras simples $(1,0$ x 0,6 m) com o sistema de fileiras duplas, Matтos (1979) е Matтos (1991) verificaram que o plantio em fileiras duplas no espaçamento de 2,0 $\times 0,6 \times 0,6 \mathrm{~m}$, proporcionou aumentos de $32 \%$ e $90 \%$ na produtividade de raízes de mandioca, respectivamente. Já em trabalho realizado por Silva e CERETTA (1986), não foi verificada a superioridade do 
sistema de fileiras duplas $(2,0 \times 0,6 \times 0,6 \mathrm{~m}$ ou $2,8 \times$ $0,6 \times 0,6 \mathrm{~m})$ sobre fileiras simples $(1,20 \times 0,6 \mathrm{~m}) \mathrm{em}$ termos de produtividade de raízes e amido na cultura de mandioca; apenas o diâmetro e peso médio de raízes foram superiores no sistema de fileiras duplas espaçadas de $2,8 \times 0,6 \times 0,6 \mathrm{~m}$.

O milho geralmente é cultivado em fileiras simples, cujo espaçamento entre linhas recomendado pode variar de 0,7 a $1,0 \mathrm{~m}$, e com as cultivares superprecoces e precoces se tem maior produtividade de grãos em espaçamentos menores, especialmente em condições de alto nível de tecnologia (BARCELLOS, 1999; Matzenauer et al., 2001; Pereira et al., 2001). Fancelli e Dourado Neto (2000) recomendam densidade de 45.000 a 55.000 plantas ha $^{-1}$ para milho, com espaçamentos na linha entre 0,55 e $0,80 \mathrm{~m}$ entre plantas.

Com relação ao arranjo de plantas mais apropriado a ser usado no consórcio mandioca-milho para o Sul do Brasil ainda existe controvérsia, pois a maioria dos resultados é de trabalhos realizados no Nordeste, onde as condições edafoclimáticas diferem da Região Sul do Brasil (MAtTos, 1979; MAtTos et al., 1983; 1985; Bueno, 1985; Tádora e Melo, 1993). Além disso, grande parte dos trabalhos tem mostrado que o cultivo da mandioca em fileiras duplas proporciona aumento substancial na produção de raízes e ramas, independentemente do cultivo solteiro ou consorciado (MAtтos et al. 1983; 1985; 1999). Alguns autores, porém, não verificaram incrementos produtivos com o uso de fileiras duplas (BUENo, 1985; Silva e CERETTA, 1986; Gabriel Filho et al., 2003), sendo inclusive verificado decréscimos produtivos com o uso de espaçamento 2,0 $00,6 \times 0,6 \mathrm{~m}$ em fileiras duplas de mandioca (MONDARDO et al., 1983; QueIrós et al., 1988; e TÁvora et al. 1989; TÁvora e Melo, 1993).

A competição intra e interespecífica no consórcio de plantas é determinada pela disposição das plantas entre e dentro das fileiras de plantio e pela época em que se inicia a competição. Para se obter o máximo da produtividade das culturas consorciadas, deve-se minimizar a competição entre e/ou dentro das espécies consorciadas, arranjando-se de tal forma as plantas que a distribuição espacial seja a mais favorável possível para ambas as culturas. A avaliação de sistemas consorciados pode ser feita a partir de duas vertentes diferentes. De parte da experimentação científica, tenta-se explicar os fatores de crescimento e desenvolvimento vegetal das culturas envolvidas por meio das interações entre as plantas onde está incluída a competição inter e intraespecífica. De parte do agricultor, entretanto, seu interesse reside na quantidade e no valor econômico da produção obtida nos diferentes sistemas (CERETTA, 1986).
Considerando esses aspectos, a pesquisa vem utilizando com maior frequêencia um índice que permite avaliar a eficiência de sistemas consorciados, tomando por base a área cultivada. Este índice, denominado "uso eficiente da terra" (UET), representa a área de terra necessária com as culturas em cultivo solteiro para proporcionar produtividade equivalente ao obtido com as culturas consorciadas (AlMEIDA, 1982; Mattos et al., 1985; CeretTA, 1986; TÁvora et al., 1989).

O sistema consorciado é uma forma de aumentar o UET (Almeida, 1982; MAtTos et al., 1983). Ainda, os mesmos autores constatam que o maior UET foi obtido com as fileiras duplas em espaçamentos de $2,0 \times 0,6 \times 0,6 \mathrm{~m}, 2,0 \times 0,5 \times 0,5 \mathrm{~m}$ e $2,0 \times 0,7 \times 0,7 \mathrm{~m} \mathrm{e}$ foram os mais eficientes, com vantagens, respectivamente, de $84 \%, 75 \%$ e $72 \%$.

Observa-se que a mandioca tem crescimento inicial lento, o que contribui para que a competição com a cultura consorciada seja minimizada (CERETTA, 1986). Quando o milho é cultivado em consórcio com a mandioca, há ainda dúvidas a respeito de qual a época de semeadura mais apropriada. A semeadura do milho muito cedo pode causar algum prejuízo no desempenho da mandioca, enquanto a semeadura do milho muito tarde pode acarretar o sombreamento pela cultura da mandioca, reduzindo a produtividade de grãos. MAtтos et al. (1985), em trabalho realizado em Conceição do Almeida (BA), constataram que o milho semeado 30 dias após o plantio da mandioca resultou em ganhos na produtividade da cultura da mandioca. Já Almeida (1982), em trabalho realizado em Viçosa, Minas Gerais, concluiu que a semeadura do milho no mesmo dia do plantio da mandioca resultou em diminuição na produtividade de raízes e nos componentes de produção de raízes da mandioca. Oportuno, também, é ressaltar que em trabalhos de épocas de semeadura do milho no consórcio com a mandioca é desejável que seja usado um indicador de tempo mais apropriado do que dias do calendário civil, como por exemplo, a soma térmica ou o número de folhas acumuladas na planta da mandioca, o que torna a recomendação menos dependente do local.

O desenvolvimento e o crescimento vegetal são processos relacionados, mas não são sinônimos, podendo ocorrer simultaneamente ou não. São, por isso, não raramente termos usados de forma inadequada e/ou confundidos. Desenvolvimento vegetal é o processo pelo qual plantas, órgãos ou células passam por vários estágios identificáveis durante seu ciclo de vida, enquanto crescimento vegetal é o aumento irreversível em alguma dimensão física de um indivíduo ou órgão com o tempo, como por exemplo, o aumento irreversível em massa seca (WilHelm e McMaster, 1995). 
A avaliação do crescimento e do desenvolvimento das culturas agrícolas é uma excelente maneira de quantificar a competição intra e interespecífica nos sistemas consorciados. Avaliações mais detalhadas, especialmente de variáveis do desenvolvimento da mandioca e do milho em consórcio são escassas, o que constitui mais um incentivo para esse esforço científico.

O objetivo deste trabalho foi quantificar o crescimento, o desenvolvimento e a produtividade da mandioca e do milho em diferentes arranjos de plantas em cultivo solteiro e consorciado considerando-se duas épocas de semeadura do milho.

\section{MATERIAL E MÉTODOS}

O experimento foi realizado no campo experimental do Departamento de Fitotecnia da Universidade Federal de Santa Maria, Santa Maria (RS), a $29^{\circ} 43^{\prime} \mathrm{S}, 53^{\circ} 43^{\prime} \mathrm{W}$ e $95 \mathrm{~m}$ de altitude média e clima Cfa, localizada na região fisiográfica da Depressão Central do Estado do Rio Grande do Sul, durante o ano agrícola de 2005/2006. O solo do local é uma transição entre a Unidade de Mapeamento São Pedro (Argissolo Vermelho distrófico arênico) e a Unidade de Mapeamento Santa Maria (Alissolo Hipocrômico argilúvico típico) (EMBRAPA, 1999; STRECK et al., 2002).

O preparo de solo foi realizado com duas gradagens leves. A análise química de solo na camada 0-20 $\mathrm{cm}$ indicou 3\% de matéria orgânica, 14,4 $\mathrm{mg} / \mathrm{dm}^{3}$ de $\mathrm{P}$ e $160 \mathrm{mg} / \mathrm{dm}^{3}$ de $\mathrm{K}$. Com base nas recomendações da Comissão de QUímica e FERTILIDAde Do Solo - RS/SC (2004), foram aplicados $2000 \mathrm{~kg} \mathrm{ha}^{-}$ ${ }^{1}$ de calcário dolomítico para elevar o $\mathrm{pH}$ do solo a 5,5 e $250 \mathrm{~kg} \mathrm{ha}^{-1}$ de fertilizante da fórmula 05-20-20 em área total por ocasião do plantio tomando-se por base a cultura do milho. Na cultura da mandioca, foram realizadas duas adubações de cobertura com $50 \mathrm{~kg} \mathrm{ha}^{-1}$ de uréia, sendo a primeira, quando havia nas plantas 15 a 20 folhas acumuladas na haste principal e iniciava-se o acúmulo de amido nas raízes tuberosas; a segunda aplicação ocorreu quando nas plantas havia entre 45 e 50 folhas acumuladas na haste principal e próxima do surgimento da primeira ramificação simpodial. Para a cultura do milho, também foram realizadas duas adubações de cobertura com $50 \mathrm{~kg} \mathrm{ha}^{-1}$ de uréia: a primeira ocorreu quando as plantas estavam nos estádios V3-V4 (terceira e quarta folhas expandidas respectivamente) e a segunda aplicação, quando as plantas de milho estavam em V7-V8 (sétima e oitava folhas expandidas) respectivamente (FANCELli e Dourado Neto, 2000; Comissão de Química e Fertilidade do Solo - RS/SC, 2004).
O controle de plantas daninhas foi realizado com capinas manuais e as pragas do milho (lagarta do cartucho) foram controladas com inseticida metamidofós em três aplicações. Houve complementações de irrigação por aspersão para evitar estresse hídrico nas plantas.

O delineamento experimental foi em blocos ao acaso, com doze tratamentos e três repetições. Os tratamentos foram os diferentes espaçamentos das culturas de mandioca e milho em cultivo solteiro e consorciado e estão descritos na tabela 1. Cada parcela experimental foi constituída de fileiras de 6 $\mathrm{m}$ de comprimento e 3,5 m de largura, sendo separadas por uma faixa de circulação de $2,5 \mathrm{~m}$. O número de plantas por fileira dependeu do espaçamento. As parcelas de mandioca cultivada em fileiras simples tinham quatro linhas de plantas e as parcelas de mandioca cultivada em fileiras duplas tinham também quatro fileiras, das quais duas fileiras constituíram a linha dupla central e duas formaram a bordadura. As parcelas de milho tinham quatro ou oito linhas simples, dependendo do arranjo $(0,80 \times 0,21$ ou 0,40 x 0,42 , respectivamente). A densidade de plantas das duas espécies no cultivo consorciado em fileira simples foi a metade, pois suprimiu-se uma fileira de uma cultura para cultivo da outra cultura (Tabela 1).

A variedade de mandioca usada foi a RS 13, que tem como características, hábito da ramificação tricotâmica, pecíolo verde-avermelhado, caule verdepreto, folhas obovadas com predominância de cinco lóbulos e raízes com formato cilindro-cônico, película marrom-clara, córtex e polpa branco-creme, recomendada para mesa. As manivas-semente foram obtidas da Fundação Estadual de Pesquisa Agropecuária do Rio Grande do Sul, Unidade de Taquari/RS (FEPAGRO/Taquari). Manivas-semente com $20 \mathrm{~cm}$ de comprimento foram plantadas em $27 \mathrm{de}$ setembro de 2005. Cerca de 30 dias após a emergência das plantas, foi efetuado o desbaste, deixando-se apenas uma haste por maniva (SANGOI e KRUSE, 1993).

A variedade de milho usada foi a BRS Missões, obtida da Empresa Brasileira de Pesquisa Agropecuária (EMBRAPA/Trigo), Unidade de Passo Fundo (RS). Esta variedade é de uso para grãos, os quais têm cor amarela e textura dentada, sendo recomendada para o cultivo no Rio Grande do Sul, Santa Catarina e Sul do Paraná. A semeadura foi realizada em duas épocas: a primeira em $2 / 11 / 2005$, com $50 \%$ de emergência da mandioca; e a segunda, em 29/11/2005, quando em $50 \%$ das plantas de mandioca havia cinco folhas visíveis (uma folha foi considerada visível quando as bordas de um dos lóbulos da folha não mais se tocavam) na haste principal. A semeadura foi realizada manualmente com três a quatro sementes por cova. Aos 15 dias após a emergência, foi realizado o desbaste, mantendo-se uma planta por cova. 
A data de emergência $(50 \%$ das plantas visíveis) foi determinada em cada parcela. Após a emergência da mandioca, as falhas (covas sem plantas) foram preenchidas transplantando-se manivas com plântulas que tinham sido plantadas em área adjacente. Esse procedimento foi adotado pelo fato de ter ocorrido um período chuvoso intenso (289 $\mathrm{mm}$ ) entre o plantio e a emergência, ocasionando perdas de manivas-semente por apodrecimento.

Após a emergência das plantas de mandioca, seis plantas por parcela foram marcadas para avaliação semanal de: (a) número total de folhas acumuladas na haste principal (NFHP) e em uma das hastes entre o primeiro e o segundo simpódio (NFRS), considerando-se como folha visível quando em um dos lóbulos da folha as bordas não estavam mais se tocando; (b) número de folhas verdes na haste principal (NFVHP); (c) número de folhas senescentes na haste principal (NFSHP) calculada pela diferença entre o número de folhas acumuladas e o número de folhas verdes; (d) altura da planta (Alt), considerada do nível do solo até a inserção da última folha da planta; (e) comprimento da haste (Chaste), sendo o comprimento de uma das hastes, escolhida aleatoriamente, oriundas entre a primeira e a segunda ramificação simpodial, e (f) área final (expandida) da folha $\left(\mathrm{cm}^{2}\right)$ na posição do nó 30 (AF30) e do nó 40 (AF40) na haste principal (acropetalmente). Estas folhas estão situadas na porção superior da haste principal e contribuem de forma significativa para a área foliar total da planta. Mediuse nestas folhas o comprimento do maior lóbulo e a área foliar $\left(\mathrm{AF}, \mathrm{cm}^{2}\right)$ foi calculada por: $\mathrm{AF}=\mathrm{ax}+\mathrm{bx}^{2}+\mathrm{cx}^{3}$ em que $x$ é o comprimento $(\mathrm{cm})$ do maior lóbulo e os coeficientes $\mathrm{a}, \mathrm{b}$ e c foram estimados por regressão polinomial, usando-se 80 folhas de diferentes tamanhos pela coleta em diferentes porções em plantas de bordadura. Em cada uma dessas 80 folhas mediuse o comprimento do maior lóbulo (x) e a AF foi estimada pelo método das fotocópias. A equação polinomial de $3 .^{\circ}$ grau foi a que melhor se ajustou aos dados e os valores estimados dos coeficientes foram: a $=3,2792 ; b=0,1607$ e $c=0,0402\left(r^{2}=0,92\right)$.

Nas plantas marcadas de mandioca foram anotados ainda o número final de folhas na haste principal até a primeira ramificação simpodial (NFFHP), número final de folhas em uma das hastes entre a primeira e a segunda ramificação simpodial (NFFRS) e a data (50\%) do surgimento da primeira e da segunda ramificação simpodial.

A colheita da mandioca foi realizada em 6 de junho de 2006, quando as plantas tinham perdido quase todas as folhas e estavam entrando no período de repouso invernal, que no Rio Grande do Sul é de três meses (junho a agosto). 
Foram determinados a produtividade de raízes $\left(t \mathrm{tha}^{-1}\right)$ e os componentes de produção massa fresca de raízes e número de raízes por unidade de área de raízes comercializáveis $(R C)$ e não comercializáveis (RNC). Consideraram-se como raízes comercializáveis as que tinham comprimento maior que $10 \mathrm{~cm}$ e diâmetro maior que $2 \mathrm{~cm}$ e como raízes não comercializáveis as demais raízes. Para a determinação dos componentes de produção da mandioca foram colhidas as seis plantas marcadas para a contagem e pesagem das RC e RNC. Foram selecionadas ao acaso $10 \mathrm{RC}$ e $10 \mathrm{RNC}$ inteiras, pesadas e colocadas em estufa a $60^{\circ} \mathrm{C}$ até massa constante visando a determinação da massa seca (MS).

Seis plantas de milho foram também marcadas por parcela experimental após a emergência nas quais foi anotado, semanalmente: (a) o número de folhas acumuladas (NF), considerando-se como NF as folhas com colar visível mais uma acima da última com colar visível; (b) o número de folhas verdes (NFV); (c) o número de folhas senescentes (NFS), pela diferença do NF - NFV; (d) a altura (Alt) da planta, do nível do solo até a inserção da última folha da planta (acropetalmente); (e) a área final (expandida) da folha $\left(\mathrm{cm}^{2}\right)$ na posição do nó 15 (AF15) e nó 18 (AF18), calculada por: $\mathrm{AF}=\mathrm{L} \times \mathrm{C} \times \mathrm{FC}$, em que $\mathrm{L}$ é a maior largura da folha $(\mathrm{cm}), \mathrm{C}$ é o comprimento da folha $(\mathrm{cm})$ e $\mathrm{FC}=0,73$ (MCKeE, 1964). Estas duas folhas foram selecionadas por estarem fotossinteticamente ativas durante a fase reprodutiva. Nas mesmas plantas marcadas, também se determinou o número final de folhas no colmo principal e a data $(50 \%$ das plantas marcadas) do pendoamento, antese, embonecamento e maturação fisiológica seguindo os critérios descritos em Fancelli e Dourado Neto (2000).

A colheita do milho foi realizada em 28 de março de 2006 para o milho semeado na primeira época e 25 de abril de 2006, para o milho da segunda época. A produtividade e os componentes de produção foram obtidos das linhas centrais da parcela experimental. Para a determinação dos componentes de produção do milho foram colhidas todas as espigas da área útil da parcela experimental. No momento da colheita foram contados o número de espigas e o número de plantas em cada parcela experimental. De cada parcela experimental foram selecionadas, ao acaso, dez espigas para determinação dos demais componentes de produção: número de grãos espiga ${ }^{-1} \mathrm{e}$ massa de cem grãos. Para obter o número de grãos espiga ${ }^{-1}$ foi contado o número médio de grãos de quatro fileiras de grãos multiplicado pelo número de fileiras de cada uma das dez espigas. Foram utilizadas quatro amostras de cada parcela experimental contendo cem grãos e levados na estufa a $60{ }^{\circ} \mathrm{C}$ para secagem até massa constante. Pesou-se cada amostra e multiplicou-se por 1,13 para calcular a produtividade em base de $13 \%$ de umidade. Com estes dados calculou-se a produtividade em $\mathrm{tha}^{-1} \mathrm{da}$ seguinte maneira (BERGAMASCHI et al., 2004):

- Massa de grãos espiga ${ }^{-1}=($ Massa média de 100 grãos $\mathrm{x} \mathrm{n.} .^{\circ}$ de grãos espiga $\left.{ }^{-1}\right) / 100$ grãos;

- Massa de grãos planta ${ }^{-1}=$ Massa de grãos espiga $^{-1} \times n^{\circ}{ }^{\circ}$ espigas planta ${ }^{-1}$;

- Massa de grãos parcela ${ }^{-1}=$ Massa de grãos planta $^{-1} \times$ n. $^{\circ}$ de plantas parcela ${ }^{-1} ; \mathrm{e}$,

- Produtividade $\left(\mathrm{t} \mathrm{ha}^{-1}\right)=$ Massa de grãos $(\mathrm{kg})$ $\mathrm{m}^{-2} \times 10.000 \mathrm{~m}^{2} \mathrm{ha}^{-1} \times 1 \mathrm{t} 1000 \mathrm{~kg}^{-1}$

A soma térmica diária $\left(\mathrm{STd},{ }^{\circ} \mathrm{C}\right.$ dia $)$, a partir da emergência das plantas, foi calculada por STd $=(\mathrm{Tm}$ $\mathrm{Tb})^{*} 1$ dia (ARNold, 1960), em que Tm é a temperatura média diária do ar calculada pela média aritmética das temperaturas mínima e máxima do ar e $\mathrm{Tb}$ é a temperatura-base considerada como $14{ }^{\circ} \mathrm{C}$ para mandioca (Schons et al., 2007) e $10{ }^{\circ} \mathrm{C}$ para milho (Westphalen e Maluf, 1984; Lozada e Angelocci, 1999; Fancelli e Dourado Neto, 2000). Apesar de constatarse que em trabalhos anteriores alguns genótipos de milho têm $\mathrm{Tb}=8^{\circ} \mathrm{C}$ (BARBANO et al., 2001; BRUNINI et al., 2001) neste estudo, foram considerados $10^{\circ} \mathrm{C}$ como a $\mathrm{Tb}$ do milho, pois não se conhece a $\mathrm{Tb}$ desta variedade. A soma térmica acumulada $\left(\mathrm{STa},{ }^{\circ} \mathrm{C}\right.$ dia) foi calculada pela soma das STd. Os valores de temperatura mínima e máxima diárias do ar para o período experimental foram medidos na Estação Climatológica Principal, pertencente ao $8 .^{\circ}$ Distrito de Meteorologia - Instituto Nacional de Meteorologia e localizada aproximadamente a $100 \mathrm{~m}$ da área experimental.

A velocidade de aparecimento de folhas nas culturas de mandioca e de milho foi estimada pelo filocrono, definido como o tempo necessário para o aparecimento de uma folha na haste ou colmo (SKINNER e Nelson, 1995; RickMAN e Klepper, 1995; Wilhelm e McMaster, 1995). Uma unidade de tempo freqüentemente utilizada para representar tempo fisiológico em plantas é a soma térmica ou soma de calor $\left({ }^{\circ} \mathrm{C}\right.$ dia). $\mathrm{O}$ filocrono neste caso é o acúmulo térmico necessário para o aparecimento de uma folha $\left({ }^{\circ} \mathrm{C}\right.$ dia folha $\left.{ }^{-1}\right)$. Foi realizada uma regressão linear entre número de folhas acumuladas na haste/colmo e STa a partir da emergência em cada cultura. O filocrono foi estimado como inverso do coeficiente angular da regressão linear entre NF e STa a partir da emergência (KLePPer et al., 1982; KIRBY, 1995; XuE et al., 2004). Na mandioca, estimou-se o filocrono da haste principal até a primeira ramificação simpodial (Filo1) e da haste entre a primeira e a segunda ramificação simpodial (Filo2) e no milho o filocrono do colmo principal. 
Também foi calculada a duração, em ${ }^{\circ} \mathrm{C}$ dia, das fases de desenvolvimento da mandioca: emergência - primeira ramificação simpodial $\left(\mathrm{ST}_{\mathrm{EM}}\right.$ RS1); primeira ramificação simpodial - segunda ramificação simpodial ( $\left.\mathrm{ST}_{\mathrm{RS} 1-\mathrm{RS} 2}\right)$, e do milho: emergência - pendoamento $\left(\mathrm{ST}_{\mathrm{EM}-\mathrm{PE}}\right)$; pendoamento - maturação fisiológica $\left(\mathrm{ST}_{\mathrm{PE}-\mathrm{MF}}\right)$ e emergência maturação fisiológica ( $\left.\mathrm{ST}_{\mathrm{EM}-\mathrm{MF}}\right)$.

O uso eficiente da terra (UET) (Mattos, 1979; Almeida, 1982; Mattos, et al., 1983; Vieira, 1984; Mattos et al., 1985; Ceretta, 1986; Mattos et al., 2005a,b) foi calculado por: UET $=(\mathrm{RMaC} /$ $\mathrm{RMaS})+(\mathrm{RMiC} / \mathrm{RMiS})$, em que $\mathrm{RMaC}$ é a produtividade de raízes totais $(\mathrm{RC}+\mathrm{RNC})$ da mandioca em consórcio; RMaS, a produtividade de raízes totais $(R C+R N C)$ da mandioca cultivada de forma solteira do tratamento T1; RMiC, a produtividade de grãos do milho em consórcio e RMiS, a produtividade de grãos do milho cultivado na forma solteira do tratamento T4.

Os dados foram submetidos à análise da variância e quando houve efeito significativo para tratamentos, foi aplicado o teste de Scheffé para os contrastes específicos referentes aos efeitos do milho e da mandioca em consórcio (Tabela 2).

\section{RESULTADOS E DISCUSSÃO}

As temperaturas máximas diárias alcançaram valores superiores a $35^{\circ} \mathrm{C}$ em 22 dias em novembro de 2005 a março de 2006, enquanto as temperaturas mínimas diárias atingiram valores entre 0 e $5^{\circ} \mathrm{C}$, em quatro dias em maio de 2006. O fotoperíodo foi crescente no início do experimento até $15 \mathrm{~h}$ no solstício de verão e decrescente no restante do experimento até aproximadamente $11 \mathrm{~h} \mathrm{em}$ direção ao solstício de inverno, como resultado da latitude deste local. Houve ocorrência de chuva ao longo do período experimental, com intensidade maior durante o plantio-emergência. O brilho solar foi crescente do início da estação de primavera-verão durante a fase vegetativa das duas culturas. $\mathrm{O}$ declínio do brilho solar diário no período de verão-outono coincidiu com os períodos de acúmulo de amido na mandioca e enchimento de grão na cultura do milho.

O crescimento em altura das plantas de mandioca foi lento no início do experimento, aumentando rapidamente até aparecer a primeira ramificação simpodial, aos 75 dias após a emergência (DAE), quando a altura foi de 1,60 m e o número final de folhas na haste principal foi de 53 folhas. A partir desse momento, houve redução na velocidade de crescimento em altura por duas razões: as plantas perderam a dominância apical e ocorreu modificação na direção do crescimento das novas ramificações para iniciar o primeiro simpódio, sendo oblíquo em relação ao nível do solo.

Em média, três novos ramos iniciaram lentamente o crescimento em altura sem dominância entre os novos ramos. O aparecimento da segunda ramificação simpodial ocorreu aos $141 \mathrm{DAE}$, quando a altura foi de $2,94 \mathrm{~m}$ e o número de folhas entre a primeira e a segunda ramificação simpodial foi de 47 folhas.

Não houve diferença estatística entre os tratamentos (Tabelas 3 e 4) para a variável altura das plantas de mandioca. Isso significa que o arranjo de plantas e a presença de plantas de milho, independente da época de semeadura no consórcio, não afetaram significativamente o crescimento em altura das plantas de mandioca. A área final das folhas dos nós 30 e 40 também não foi afetada pelos tratamentos. Da mesma forma, o número de folhas verdes na planta de mandioca ao longo do experimento também foi similar entre os tratamentos (Dados não apresentados).

Tabela 2. Descrição e efeito dos contrastes definidos para os tratamentos da Tabela 1. Santa Maria (RS), 2005/2006

\begin{tabular}{lll}
\hline Contraste & Descrição do efeito envolvido & Efeito \\
\hline Y1 & Época 1 vs época 2 do milho sem mandioca & $(\mathrm{T} 3, \mathrm{~T} 4)$ vs (T8, T9) \\
Y2 & Época 1 vs época 2 do milho com mandioca & $(\mathrm{T} 5, \mathrm{~T} 6, \mathrm{~T} 7)$ vs $(\mathrm{T} 10, \mathrm{~T} 11, \mathrm{~T} 12)$ \\
Y3 & Efeito do milho sobre a mandioca na época 1 & $(\mathrm{~T} 1, \mathrm{~T} 2) \mathrm{vs}(\mathrm{T} 5, \mathrm{~T} 6)$ \\
Y4 & Efeito do espaçamento do milho (sem mandioca) & $(\mathrm{T} 3, \mathrm{~T} 8)$ vs (T4, T9) \\
Y5 & Efeito do espaçamento de mandioca sem milho & $\mathrm{T} 1$ vs T2 \\
Y6 & Efeito do espaçamento da mandioca com milho na época 1 & $\mathrm{~T} 5$ vs T6 \\
Y7 & Efeito do espaçamento da mandioca com milho na época 2 & T10 vs T11 \\
Y8 & Efeito do espaçamento do milho sobre a mandioca pareada & (T6, T11) vs (T7, T12) \\
Y9 & Efeito da época do milho pareado na mandioca pareada & T7 vs T12 \\
\hline
\end{tabular}




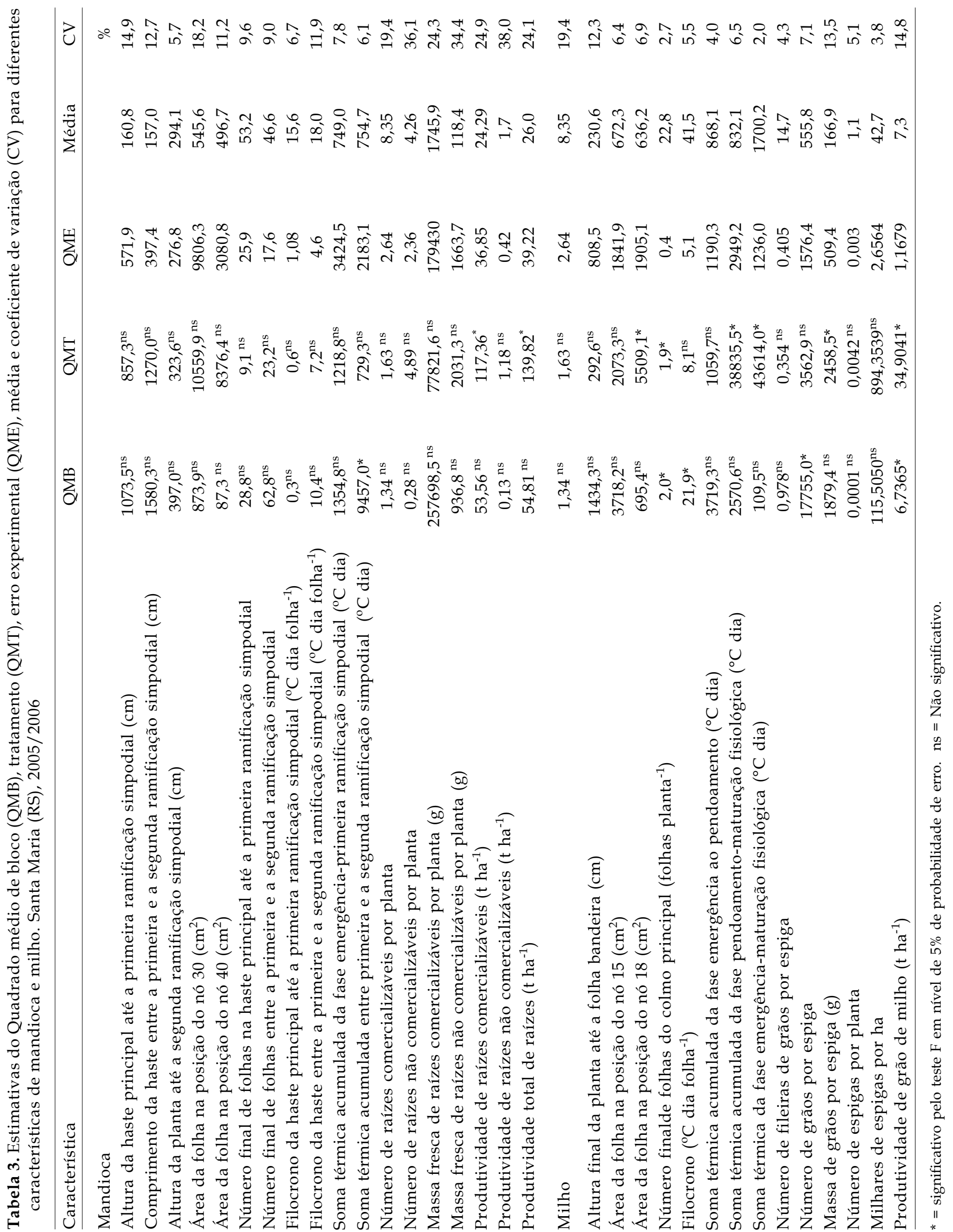


Pela análise estatística observa-se que também não houve efeito significativo dos tratamentos sobre as variáveis do desenvolvimento da mandioca (filocrono e STa das fases, Tabelas 3 e 4). Assim, esses resultados atestam que, como ocorreu com o crescimento, o desenvolvimento da planta de mandioca não foi afetado significativamente pelo arranjo de plantas e o consórcio com o milho.

O crescimento em altura de plantas de milho seguiu uma variação sigmóide típica ao longo do experimento e similar entre os tratamentos (dados não apresentados). A análise estatística revelou que não houve diferença de altura final das plantas de milho (Tabelas 3 e 5). Para as outras duas variáveis de crescimento analisadas (AF15 e AF18), houve efeito significativo de tratamentos apenas para AF18, o que não foi detectado pelos contrastes (Tabela 6). O número de folhas verdes (NFV) em milho foi diferente entre os tratamentos, mas não detectados pelos contrastes (Tabela 6). Por esses resultados, verifica-se que o arranjo das plantas e o consórcio com a mandioca não afetaram significativamente o crescimento das plantas de milho.

Com relação às variáveis de desenvolvimento do milho (filocrono e STa das fases), não houve efeito significativo de tratamento para as variáveis filocrono e $\mathrm{ST}_{\mathrm{EM}-\mathrm{PE}}$ (Tabelas 3 e 5). Para as variáveis NFF, $\mathrm{ST}_{\mathrm{PE}-\mathrm{MF}} \mathrm{e}$ STEEM-MF houve efeito significativo de tratamentos, mas para os contrastes definidos na tabela 2 houve efeito significativo (Tabela 6) apenas para as variáveis $\mathrm{ST}_{\mathrm{PE}-\mathrm{MF}}$ e $\mathrm{ST}_{\mathrm{EM}-\mathrm{MF}}$ nos contrastes Y1 e Y2 (Época 1 vs Época 2, Tabela 2). Observou-se maior duração em graus dia, da fase $\mathrm{ST}_{\mathrm{PE}-\mathrm{MF}}$, e que resultou na maior duração da fase $\mathrm{ST}_{\mathrm{EM}-\mathrm{MF}}$ do milho, na primeira época de semeadura (Tabela 5), visto que a maturação fisiológica (MF) ocorreu apenas oito dias mais tarde, na segunda época de semeadura, apesar da semeadura, emergência e pendoamento ter ocorrido, respectivamente, em 27, 24 e 20 dias.

Os componentes de produção (número de raízes e massa fresca por planta) da mandioca não foram afetados significativamente pelos tratamentos (Tabela 3). Significa que a produtividade de raízes de mandioca não foi afetada pelo arranjo de plantas de mandioca cultivada de forma solteira nem pela presença do milho (espaçamento e época de semeadura) no consórcio. Houve efeito significativo de tratamentos para as variáveis $R C$ e RT de mandioca. Este efeito ocorreu porque a produtividade de raízes $\left(\mathrm{t} \mathrm{ha}{ }^{-1}\right)$ foi a metade nos tratamentos $\mathrm{T} 5 \mathrm{e}$ T10 (Tabela 4). 

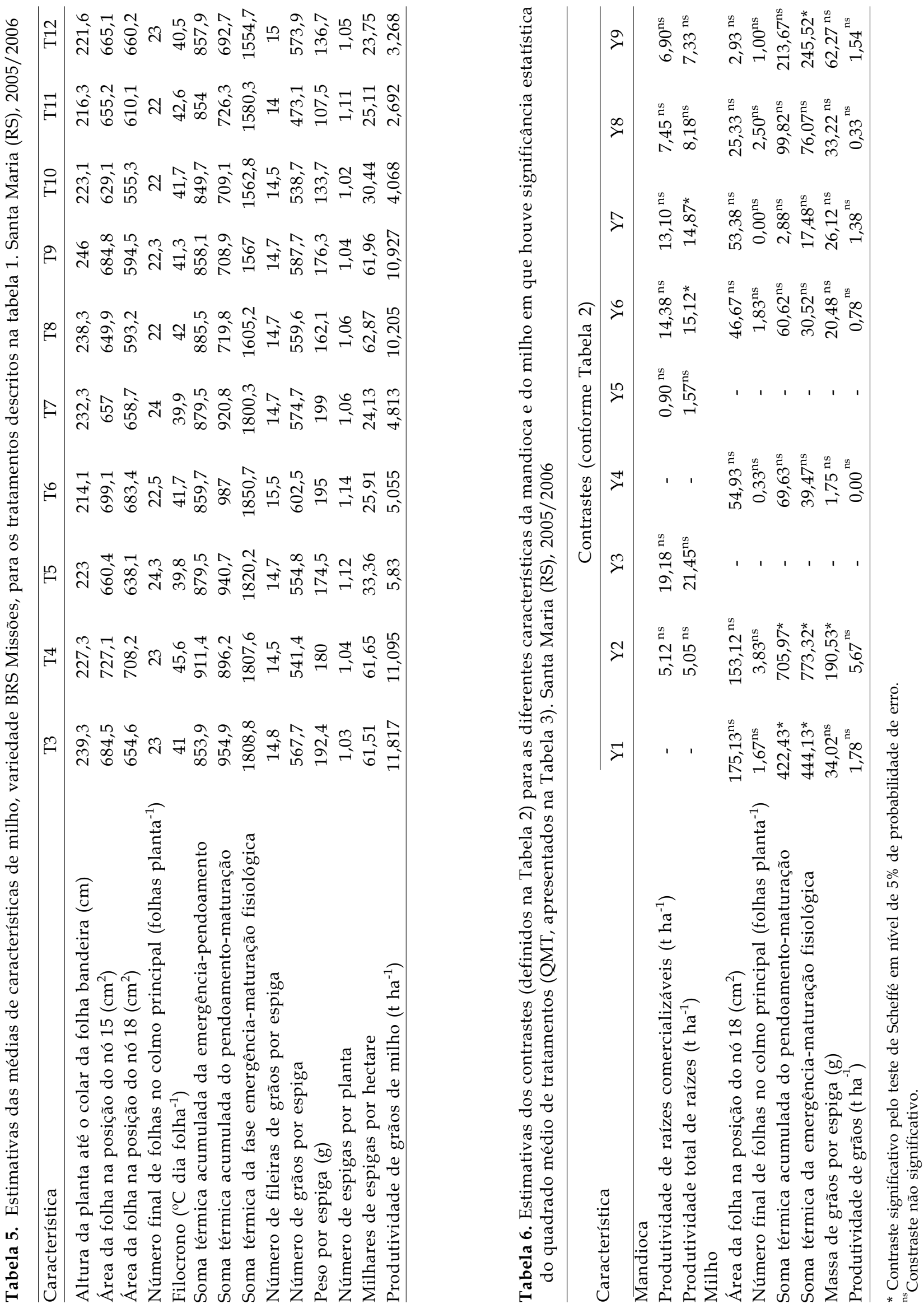
Nesses tratamentos de consórcio, o milho e a mandioca foram arranjados em fileiras simples (Tabela 1) e com linhas intercaladas de cada espécie, o que levou a ter a metade do número de plantas por unidade de área em cada cultura, comparado ao cultivo solteiro das duas espécies ou com o cultivo em consórcio quando a mandioca é arranjada em fileiras duplas.

No entanto, os contrastes de interesse nesse estudo (Tabela 6) não foram significativos para ambas as variáveis RC e RT. Esses resultados revelam que a competição, interespecífica nos consórcios e intraespecífica no cultivo solteiro, não teve efeito significativo sobre o número e tamanho das raízes das plantas da mandioca. Assim, permite-se concluir que os espaçamentos e as densidades das duas espécies no cultivo em consórcio foram apropriados e não comprometeram seu desempenho em relação ao cultivo solteiro. O ganho de produtividade que se tem no consórcio é, portanto, resultado do melhor aproveitamento do espaço destinado a cada espécie na lavoura.

Os componentes de produção de milho também não foram afetados pelos tratamentos (Tabela 3). A exceção foi a variável massa de grãos por espiga (MGPE), que no contraste Y2 foi significativo (Tabela 6) indicando que a MGPE foi significativamente maior no milho em consórcio semeado na primeira época. Significa que a grande maioria dos tratamentos não afetou o desempenho individual das plantas de milho, ou seja, o milho não foi afetado pela competição com a mandioca nas diferentes combinações de espaçamentos, nem pelo espaçamento do milho solteiro, nem pela época de semeadura (tanto em cultivo solteiro como em consórcio). Houve efeito significativo de tratamentos para produtividade de grãos, principalmente devido à baixa produtividade de grãos por unidade de área nos tratamentos de consórcio com a mandioca. No entanto, os contrastes definidos nesse estudo não foram significativos (Tabela 6), indicando que a maior MGPE de milho na primeira época (contraste Y2) não refletiu significativamente em maior produtividade de grãos, de forma que o contraste Y2 para a produtividade de grãos não foi significativo (Tabela 6). Infere-se, portanto, que a competição, interespecífica nos consórcios e intraespecífica na cultura solteira, não teve efeito significativo sobre a produtividade e os componentes de produção do milho.

No presente estudo, a produtividade das raízes de mandioca da variedade RS13 atingiu $33,4 \mathrm{t} \mathrm{ha}^{-1}$ em cultivo solteiro (Tabela 4). Esse nível de produtividade é similar obtido em cultivos de mandioca em Pacajús, Ceará (Távora e Melo, 1993) e Cruz das Almas, Bahia (Matтos et al., 1999) e é inferior às produtividades obtidas em cultivos em Marechal Cândido Rondon, Paraná (Gabriel FilHo et al., 2003). Os tratamentos (T5 e T10) de mandioca $(0,8 \times 0,78 \mathrm{~m})$ consorciado com milho $(0,8 \times 0,21 \mathrm{~m})$ foram os que resultaram em menor produtividade de raízes (Tabela 4), tendo como causa provável a baixa densidade de plantas. Esse nível de produtividade é similar às produtividades de mandioca obtidas em cultivos em Guaíba (RS), segundo SiLva e CERETTA, 1986.

Quando se analisou o uso eficiente da terra (UET) ficou evidente que os tratamentos em que foi utilizado o consórcio, com a mandioca em fileira dupla no espaçamento $1,6 \times 0,5 \times 0,6 \mathrm{~m}$, foram os mais eficientes (Tabela 1). Com esses tratamentos houve incrementos na exploração da terra de $32 \%$ e $34 \%$, comparados com os tratamentos em fileiras duplas de mandioca consorciada com milho espaçado de $0,4 \mathrm{x}$ $0,42 \mathrm{~m}$ e $0,8 \times 0,21 \mathrm{~m}$ respectivamente, semeado logo após a emergência da mandioca. Já o consórcio em fileiras duplas de mandioca com milho em fileiras espaçadas de $0,8 \times 0,21 \mathrm{~m}$, semeado quando nas plantas de mandioca havia cinco folhas acumuladas, foi $16 \%$ superior se comparado com o cultivo solteiro de milho com o mesmo espaçamento.

Outra maneira de interpretar os dados de UET neste estudo (Tabela 1) é que, por exemplo, tomandose as produtividades obtidas nas culturas consorciadas em fileiras duplas de mandioca para os tratamentos T6 e T7, com semeadura de milho logo após a emergência da mandioca, com espaçamentos de milho em fileiras de $0,8 \times 0,21 \mathrm{~m}$ ou duas fileiras de milho de 0,4 x 0,42 m, são necessários 1,34 ha e 1,32 ha respectivamente, em cultivo das culturas de mandioca e milho de forma solteira para obter as produtividades equivalentes a 1,0 ha de cultivo consorciado. Para o mesmo espaçamento de fileiras duplas de mandioca com milho (T11), com semeadura de milho $(0,8 \times 0,21 \mathrm{~m})$ semeado quando a mandioca estava com cinco folhas acumuladas, são necessários 1,16 ha em cultivo das culturas de mandioca e milho de forma solteira para obter as produtividades equivalentes a 1,0 ha de cultivo consorciado.

\section{CONCLUSÕES}

1. A competição interespecífica entre as culturas da mandioca e do milho em cultivo consorciado nos espaçamentos utilizados neste estudo não afeta parâmetros de crescimento e desenvolvimento e a produtividade das duas espécies quando comparado com o cultivo solteiro. 
2. No cultivo consorciado de mandioca e milho, recomenda-se o arranjo de mandioca em fileiras duplas no espaçamento de $1,6 \times 0,5 \times 0,6 \mathrm{~m}$ com uma fileira de milho no espaçamento de $0,8 \mathrm{~m} \times 0,2 \mathrm{~m}$ ou duas fileiras no espaçamento de $0,4 \mathrm{~m} \times 0,4 \mathrm{~m}$ dispostas entre as fileiras duplas de mandioca, com semeadura na emergência da mandioca.

\section{AGRADECIMENTOS}

O primeiro autor agradece à ASCAR-EMATER (RS) pela sua liberação para a realização deste estudo como parte do seu programa de Mestrado na UFSM. Os autores N.A. Streck, L. Storck e G.A. Buriol agradecem ao $\mathrm{CNPq}$ pela bolsa de Produtividade em Pesquisa.

\section{REFERÊNCIAS}

ALMEIDA, P.A. Consórcio de mandioca (Manihot esculenta) com milho, amendoim e batata. Viçosa: UFV, 1982, $49 \mathrm{f}$. Dissertação (Mestrado em Fitotecnia) - Programa de PósGraduação em Fitotecnia, Universidade Federal de Viçosa, 1982.

ARNOLD, C.Y. Maximum-minimum temperatures as a basis for computing heat units. Proceedings of the American Society for Horticultural Sciences, Boston, v.76, n.1, p.682-692, 1960.

BARBANO, M.T.; DUARTE, A.P.; BRUNINI, O.; RECO, P.C.; PATERNIANI, M.E.A.G.Z.; KANTHACK, R.A.D. Temperaturabase e acúmulo térmico no subperíodo semeaduraflorescimento masculino em cultivares de milho no Estado de São Paulo. Revista Brasileira de Agrometorologia, Santa Maria, v.9, n.2, p.261-268, 2001.

BARCELLOS, L.A.R. Milho Varietal. Santa Maria: ESREG Depressão Central-EMATER/RS, 1999. 2 p. (Informativo Técnico Regional, 9)

BERGAMASCHI, H.; DALMAGO, G.A.; BERGONCI, J.I.; BIANCHI, C.A.M.; MULLER, A.G.; COMIRAM, F.; HECKLER, B.M.M. Distribuição hídrica no período crítico do milho e produção de grãos. Pesquisa Agropecuária Brasileira, Brasília, v.39, n.9, p.831-839, 2004.

BRUNINI, O.; ZULLO JUNIOR, J.; PINTO, H.S.; ASSAD, E.; SAWAZAKI, E.; DUARTE, A.P.; PATTERNIANI, M.E.Z. Riscos climáticos para a cultura de milho no estado de São Paulo. Revista Brasileira de Agrometeorologia, Santa Maria, v.9, n.3, p.519-526, 2001.

BUENO, A. Behavior of contrasting cassava genotypes grown under different spacing arrangements. Revista Brasileira de Mandioca, Cruz das Almas, v.4, n.1, p.33-42, 1985.

CERETTA, C.A. Sistemas de cultivo de mandioca em fileiras simples e duplas em monocultivo e consorciada com girassol. Porto Alegre: UFRGS, 1986, 120f. Dissertação (Mestrado em Agronomia) - Programa de Pós-Graduação em Agronomia, Universidade do Rio Grande do Sul, 1986.
COMISSÃO DE QUÍMICA E FERTILIDADE DO SOLO - RS/ SC. Manual de adubação e calagem para os Estados do Rio Grande do Sul e Santa Catarina. Porto Alegre: Sociedade Brasileira de Ciências do Solo. 10.ed., 2004. 400p.

EMBRAPA. Sistema Brasileiro de Classificação de Solos. Brasília: EMBRAPA - SPI; EMBRAPA - CNPS, 1999. 412p.

FANCELLI, A.L.; DOURADO NETO, D. Produção de Milho. Guaíba: Ed. Agropecuária, 2000. 360p.

GABRIEL FILHO, A.; STROHHAECKER, L.; FEY, E. Profundidade e espaçamento da mandioca no plantio direto na palha. Ciência Rural, Santa Maria, v.33, n.3, p.461-467, 2003.

IBGE. Produção Agrícola Municipal, 2006. Disponível em: http://www.ibge.gov.br. Acesso em 3/12/2007.

KIRBY, E.J. Factors affecting rate of leaf emergence in barley and wheat. Crop Science, Madison, v.35, n.1, p.11-19, 1995.

KLEPPER, B.; RICKMAN, R.W.; PETERSON, C.M. Quantitative characterization of vegetative development in small cereal grains. Agronomy Journal, Madison, v.74, p.798-792, 1982.

LOZADA, B.I.; ANGELOCCI, L.R. Determinação da temperatura-base e de graus-dia para estimativa da duração do subperíodo da semeadura à floração de um híbrido de milho (Zea mays). Revista Brasileira de Agrometeorologia, Santa Maria, v.7, n.1, p.31-36, 1999.

MATTOS, P.L.P. Plantio de mandioca consorciada em fileiras duplas: Mandioca em foco. Cruz das Almas: EMBRAPACNPMF, 1991. 2p. (Comunicado Técnico, 6)

MATTOS, P.L.P. Plantio de mandioca em fileiras duplas. Cruz das Almas: EMBRAPA- CNPMF, 1979. 5p. (Comunicado Técnico, 2)

MATTOS, P.L.P.; CALDAS, R.C.; SOUZA, A.S. Mandioca plantada em fileiras duplas consorciada com milho. Revista Brasileira de Mandioca, Cruz das Almas, v.2, n.1, p.55-58, 1983.

MATTOS, P.L.P.; SOUZA, A.S.; CALDAS, R.C. Mandioca consorciada com milho. Revista Brasileira de Mandioca, Cruz das Almas, v.4, n.2, p.61-67, 1985.

MATTOS, P.L.P.; SOUZA, L.S.; SOUZA, J.S.; CALDAS, R.C. Mandioca em fileiras duplas e simples consorciada com caupi e milho. Cruz das Almas: EMBRAPA- CNPMF, 1999. p.3. (Comunicado Técnico, 59)

MATTOS, P.L.P.; SOUZA, L.S.; SOUZA, J.S.; CALDAS, R.C. Consorciação da mandioca plantada em fileiras duplas e simples com culturas de ciclo curto. I. mandioca $x$ caupi $x$ milho. Revista Brasileira de Mandioca, Cruz das Almas, v.18, n.1, p.25-30, 2005a.

MATTOS, P.L.P.; SOUZA, L.S.; SOUZA, J.S; CALDAS, R.C. Consorciação da mandioca plantada em fileiras duplas e simples com culturas de ciclo curto. II. mandioca $x$ caupi $x$ milho. Revista Brasileira de Mandioca, Cruz das Almas, v.18, n.1, p.31-36, 2005b. 
MATZENAUER, R.; MALF, J.R.T.; VIOLA, E.A.; BISOTTO,V. Indicações técnicas para a cultura de milho no Estado do Rio Grande do Sul. Porto Alegre: FEPAGRO, 2001. 195p. (Boletim Técnico, 7)

McKEE, G.W. A coefficient for computing leaf area in hybrid corn. Agronomy Journal, Madison, v.52, n.2, p. 240-241, 1964.

MONDARDO, E.; MORAES, O.; FROSI, J.F.; TERNES, M. Mandioca em fila dupla consorciada com leguminosas no sul de Santa Catarina. Florianópolis: EMPASC, 1983. p.7. (Comunicado técnico, 63)

OYARZÁBAL, G.E. Aproveitamento Integral da mandioca no Rio Grande do Sul: Rações à base de mandioca. Porto Alegre: EMATER/RS, 1995.64p.

PEREIRA, L.R.; PORTO, M.P.; WINKLER, E.I.; GUADAGNIN, J.P. Cultivares. In: Indicações técnicas para a cultura de milho no estado do Rio Grande do Sul. Porto Alegre: FEPAGRO, 2001. p.74-84. (Boletim Técnico, 7)

QUEIROZ, G.M.; TAVORA, F.J.A.F.; PINHO, J.L.N.; MELO, F.I.O. Arranjo espacial e população de plantio em mandioca consorciado com caupi. Revista Brasileira de Mandioca, Cruz das Almas, v.7, n.2, p.1-6, 1988.

RAO, M.R.; MORGADO, L.B. Consorciação com a cultura da mandioca no Nordeste do Brasil: resultados atuais e perspectivas para futuras pesquisas. Petrolina: EMBRAPACPATSA, 1985. 22p. (Documentos 32)

RICKMAN, R.W.; KLEPPER, B.L. The phyllochron: Where do we go in the future? Crop Science, Madison, v. 35, n. 1, p. 4449, 1995.

SANGOI, L.; KRUSE, N.D. Acúmulo e distribuição de matéria seca em diferentes frações da planta de mandioca no Planalto Catarinense. Pesquisa Agropecuária Brasileira, Brasília, v.28, n.10, p.1151-1164, 1993.

SCHONS, A.; STRECK, N.A.; KRAULICH, B.; PINHEIRO, D.G.; ZANON, A.J. Emissão de folhas e início de acumulação de amido em raízes de uma variedade de mandioca em função da época de plantio. Ciência Rural, Santa Maria, v.36, n.6, p.1586$1592,2007$.

SILVA, P.R.F.; CERETTA, C.A. Sistemas de cultivo de mandioca. I. Monocultivo em fileiras simples e duplas. Revista Brasileira de Mandioca, Cruz das Almas, v.5, n.2, p.55-63, 1986.

SKINNER, R.H.; NELSON, C.J. Elongation of the grass leaf its relationship to the phyllochron. Crop Science, Madison, v.35, n.1, p.4-10, 1995.

STRECK, E.V.; KAMPF, N.; DALMOLIN, R.S.D.; KLAMT, E.; NASCIMENTO, P.C.; SCHNEIDER, P. Solos do Rio Grande do Sul. Porto Alegre: EMATER/RS; UFRGS, 2002. 126p.

TÁVORA, F.J.A.F.; MELO, F.I.O. Crescimento e produção da mandioca submetida a dois arranjos de plantio. Pesquisa Agropecuária Brasileira, Brasília, v.28, n.7, p.823-832, 1993.
TÁVORA, F.J.A.F.; SILVA, F.P.; MELO, F.I.O.; COSTA NETO, F.V. Consórcio da mandioca com culturas leguminosas de ciclo curto. Revista Brasileira de Mandioca, Cruz das Almas, v.8, n.1, p.31-40, 1989.

USDA [United State Department of Agriculture]. Wheat, rice and corn area, yield and production. 2007. Disponível em: http://www.faz.usda.gov/psd. Acesso em 3/12/2007.

VIEIRA, C. Cultivo consorciado de mandioca com feijão. Informe Agropecuário, Belo Horizonte, v.10, n.118, p.43-9, 1984.

WESTPHALEN, S. L.; MALUF, J.R.T. Zoneamento para a mandioca no Rio Grande do Sul. In: IPAGRO Informa. Porto Alegre: CORAG, n. 27, p.5-8, 1984.

WILHELM, W.W.; McMASTER, G.S. Importance of the phyllochron in studying development and growth in grasses. Crop Science, Madison, v.35, n.1, p.1-3, 1995.

XUE, Q.; WEISS, A.; BAENZIGER, P.S. Predicting leaf appearance in field-grown winter wheat: evaluating linear and non-linear models. Ecological Modeling, Amsterdam, v.175, p.261-270, 2004. 